\title{
A Systematic Review and Meta-Analysis of Seasonal Influenza Vaccination of Health Workers
}

\author{
Tingting Li ${ }^{1,+} \oplus$, Xiaoling $\mathrm{Qi}^{2,+}$, Qin $\mathrm{Li}^{1,+}{ }^{\dagger}$, Wenge Tang ${ }^{1}$, Kun Su ${ }^{1}$, Mengmeng Jia ${ }^{3}$, Weizhong Yang ${ }^{3}$, Yu Xia ${ }^{1}$, \\ Yu Xiong ${ }^{1}$, Li Qi ${ }^{1, *}$ and Luzhao Feng ${ }^{3, *}$
}

1 Chongqing Municipal Center for Disease Control and Prevention, Chongqing 400016, China; Lee712ting@126.com (T.L.); liqin2006@163.com (Q.L.); twg@cqcdc.org (W.T.); sukun325@163.com (K.S.); xiayucq4@hotmail.com (Y.X.); Yuri811320@163.com (Y.X.)

2 Affiliated Stomatological Hospital of Chongqing Medical University, Chongqing 400016, China; 501044@hospital.cqmu.edu.cn

3 School of Population Medicine and Public Health, Chinese Academy of Medical Sciences \& Peking Union Medical College, Beijing 100005, China; jiamengmeng@cams.cn (M.J.); yangweizhong@cams.cn (W.Y.)

* Correspondence: qili19812012@126.com (L.Q.); fengluzhao@cams.cn (L.F.)

+ These authors contributed equally to this article.

check for

updates

Citation: Li, T.; Qi, X.; Li, Q.; Tang, W.; Su, K.; Jia, M.; Yang, W.; Xia, Y.; Xiong, Y.; Qi, L.; et al. A Systematic Review and Meta-Analysis of Seasonal Influenza Vaccination of Health Workers. Vaccines 2021, 9, 1104. https:/ / doi.org/10.3390/vaccines9101104

Academic Editor:

Luis Martinez-Sobrido

Received: 12 July 2021

Accepted: 24 September 2021

Published: 29 September 2021

Publisher's Note: MDPI stays neutral with regard to jurisdictional claims in published maps and institutional affiliations.

Copyright: (c) 2021 by the authors. Licensee MDPI, Basel, Switzerland. This article is an open access article distributed under the terms and conditions of the Creative Commons Attribution (CC BY) license (https:// creativecommons.org/licenses/by/ $4.0 /)$.

\begin{abstract}
A systematic review and meta-analysis was conducted to estimate the pooled effect of influenza vaccinations for health workers (HWs). Nine databases were screened to identify randomized clinical trials and comparative observational studies that reported the effect of influenza vaccination among HWs. The risk ratio (RR), standardized mean difference, and 95\% confidence interval (CI) were employed to study the effect size using fixed/random-effect models. Subgroup analyses and sensitivity analyses were conducted accordingly. Publication bias was examined. Sixteen studies (involving $7971 \mathrm{HWs}$ from nine countries) were included after a comprehensive literature search. The combined RR regarding the incidence of laboratory-confirmed influenza was 0.36 ( $95 \%$ CI: 0.25 to 0.54 ), the incidence of influenza-like illness (ILI) was 0.69 (95\% CI: 0.45 to 1.06), the absenteeism rate was 0.63 (95\% CI: 0.46 to 0.86$)$, and the integrated standardized mean difference of workdays lost was -0.18 ( $95 \% \mathrm{CI}$ : -0.28 to -0.07 ) days/person. The subgroup analysis indicated that vaccination significantly decreases the incidence of laboratory-confirmed influenza in different countries, study populations, and average-age vaccinated groups. Influenza vaccinations could effectively reduce the incidence of laboratory-confirmed influenza, absenteeism rates, and workdays lost among HWs. It is advisable, therefore, to improve the coverage and increase the influenza vaccination count among HWs, which may benefit both workers and medical institutions.
\end{abstract}

Keywords: influenza vaccination; health workers; meta-analysis; incidence of laboratory-confirmed influenza; absenteeism rate

\section{Introduction}

Seasonal influenza is a public concern globally. It is estimated that there are about one billion cases of influenza worldwide per year, of which 3-5 million are severe cases and 0.29-0.65 million lead to influenza-related respiratory death [1,2]. Health workers (HWs) are at increased risk of influenza virus infection, which may vary depending on occupation or setting [3], and infected HWs could increase the risk of nosocomial infection and community spread $[4,5]$

Vaccination is the most effective way to prevent influenza [6,7]. The World Health Organization (WHO) considers HWs to be a priority group for influenza vaccination and reinforces this position by supporting countries to develop and implement national, seasonal immunization policies for HWs [7,8]. Most European countries recommend that HWs, at least those involved in direct patient care, are vaccinated against influenza each year [9]. Despite recommendations for influenza vaccination of HWs, vaccine coverage 
among HWs has remained far below the desired level to achieve herd immunity [10]. Influenza vaccination coverage among HWs has surpassed $75 \%$ in the United States (US) [11] and 76.8\% in the United Kingdom (UK) [12], but remains below 30\% in many other European countries [13], and covered only approximately 5\% of HWs in China in 2017-2018 [14,15]. The reasons for low coverage rates among HWs are complex, including concerns about side effects, skepticism about vaccine effectiveness, low awareness of vaccine guidelines, and the misunderstanding that influenza is not serious $[16,17]$

Evidence of the effectiveness of influenza vaccinations is important to increase the confidence of HWs and provide a rational backdrop for the future development of vaccination policies $[18,19]$. Several reviews have already evaluated the effectiveness of the influenza vaccine in HWs, with some limitations. For example, in a systematic review, $\mathrm{Ng}$ et al. evaluated the effects of seasonal vaccines among HWs based on only three randomized controlled trials (RCTs), and there was insufficient evidence suggesting that receiving an influenza vaccine reduces the incidence of influenza, number of influenza-like illness (ILI) episodes, days with ILI symptoms, or amount of sick leave taken [20]. Another review was a qualitative analysis, without quantitative results [21]. Other reviews evaluated morbidity and mortality outcomes among patients, but did not address the impact for HWs [22,23]. In this study, we performed a systematic review and meta-analysis to comprehensively evaluate and update the evidence on influenza vaccinations for HWs.

\section{Methods}

\subsection{Study Design}

We conducted this systematic review and meta-analysis based on the statement of the Preferred Reporting Items for Systematic and Meta-Analysis (PRISMA) guidelines [24,25]. According to the Centers for Disease Control and Prevention (CDC), we considered physicians, nurses, emergency medical personnel, dental professionals and students, medical and nursing students, laboratory technicians, pharmacists, hospital volunteers, and administrative staff as HWs [26]. The study protocol was registered in the International Prospective Register for Systematic Reviews (PROSPERO, registration number: CRD42020162226) [27].

\subsection{Search Strategy}

The following nine databases were searched for articles meeting the inclusion criteria: PubMed; Web of Science; EMBASE; Scopus; The Cumulative Index to Nursing and Allied Health Literature (CINAHL); The Cochrane Library; China National Knowledge Infrastructure (CNKI); Chinese Science and Technology Periodical Database; WanFang Database; The Scientific Electronic Library Online (SciELO) database. Publications in English, Chinese, and Japanese were eligible for review. This was supplemented by searching ongoing trial databases, such as ClinicalTrials.gov and the WHO International Clinical Trial Search Registry Platform. The reference lists of the included studies and relevant reviews were also manually searched. English- and Chinese-language articles were reviewed by Tingting Li and Xiaoling Qi. This review and meta-analysis was restricted to the published literature. Gray literature was not considered in this study. Gray literature is a field in library and information sciences that deals with the production, distribution, and access to multiple document types produced at all levels of the government, as well as by academics, businesses, and organizations in electronic form; the print formats of gray literature are not controlled by commercial publishing, or publishing is not the primary activity of the producing body [28].

The literature search was performed using combinations of the following search terms: Exp health personnel/OR (health* ADJ2 personnel) OR (health* ADJ2 worker*) OR (health* ADJ2 aid*) OR nurse* OR doctor* OR physician* OR care provider* OR clinician*.

\subsection{Selection Criteria}

Published articles were considered for inclusion if they met the following criteria: (1) The studies were either RCTs or comparative observational studies (cohort and case- 
control studies). (2) The articles compared the effects of influenza vaccination on HWs with a placebo or non-influenza vaccine control, or unvaccinated HWs. (3) The studies reported one of the following outcomes: incidence of laboratory-confirmed influenza; incidence of ILI; incidence of absenteeism; the number of working days lost per person. (4) The data reported were complete and could be used in the meta-analysis. (5) The data were published in peer-reviewed journals in English, Chinese, or Japanese.

We excluded studies that focused on influenza pandemics. For example, monovalent A (H1N1) pdm09 vaccines that were produced in response to the 2009 global influenza pandemic were excluded. As the focus of this work was specific to HW endpoints, we also excluded studies that solely investigated the effects of vaccines on patient-related outcomes in patients or HWs.

\subsection{Study Selection and Data Extraction}

The literature search was conducted by two teams based on the Cochrane guideline, which were guided by Li Qi and Luzhao Feng, respectively. Identified articles were independently screened by two reviewers (Xiaoling Qi and Tingting Li) for inclusion in the analysis, and for those with titles and abstracts that met the criteria, full-texts were obtained and re-screened. EndNote (X9, Clarivate, Philadelphia, PA, USA) was used to record and manage identified articles. Any discrepancies were resolved during a weekly discussion of reviewed articles by Tingting Li and Xiaoling Qi. In case of disagreement, an independent evaluation was performed by a third experienced reviewer, Li Qi. In total, about 120 published papers were discussed and finally agreed upon.

Data extraction was performed systematically by two reviewers (Tingting Li and Li Qi) using piloted standardized forms, and discrepancies were resolved by discussion to reach a consensus. The extracted data included: published information (first author's name, published year, and country); study design (RCT or observational study); participants' characteristics (sample, setting, and profession); intervention information; comparison (placebo, non-influenza vaccine, or unvaccinated HWs); outcomes (incidence of laboratoryconfirmed influenza cases or ILI in vaccination groups and comparison groups, absenteeism rate, mean workdays lost, and standard deviation in two groups); other study characteristics (duration of follow-up). Excel (Microsoft Office Professional 2016, Microsoft, Redmond, WA, USA) was utilized to manage the extracted data and information.

\subsection{Quality Assessment}

Two members of our research team (Tingting Li and Xiaoling Qi) independently assessed each included trial, and the risks of bias for RCTs and observational studies were evaluated. For RCTs, the Cochrane Collaboration tool (ROB 2.0) was used to evaluate the quality of studies [29-31], by assessing the following five domains: randomization process (including random sequence generation and allocation concealment); deviation from intended interventions; missing outcome data; measurement of the outcome; selection of the reported result. Each RCT was classified into "low risk," "of some concern," or "high risk" for each domain, and was determined to be "low risk," "of some concern," or "high risk" for overall bias.

For observational studies, the Newcastle-Ottawa Scale (NOS) was employed to evaluate the risk of bias for cohort and case-control studies [32]. The NOS uses the "star system," with a maximum of nine stars, and evaluates three domains with a total of eight items: selection; comparability; the outcome of exposure of interest. Studies with scores of seven or more stars were considered to be of high quality, five to six stars of moderate quality, and four or fewer stars of low quality [33]

\subsection{Statistical Analysis}

Data analysis was performed with STATA (version 16, StataCorp, College Station TX, USA) and all tests were two-sided. A $P$-value of 0.05 was considered to determine statistical significance unless indicated otherwise. For dichotomous and continuous outcomes, we 
calculated pooled risk ratios (RRs), or standardized mean differences (SMD) with their 95\% confidence intervals (CIs), to examine the effectiveness of influenza vaccination by the fixed-effect model (Mantel-Haenszel method) or the random-effect model (DerSimonianLaird method) if there was certain heterogeneity. We tested the statistical heterogeneity using Cochran's Q statistical-based $\chi^{2}$ and I-squared $\left(\mathrm{I}^{2}\right)$ statistics [34]. For $\mathrm{I}^{2}$ values of $0 \%$ to $30 \%$, it was determined that heterogeneity might not be important, while $\mathrm{I}^{2}$ values of $30 \%$ to $50 \%$ indicated moderate heterogeneity, $\mathrm{I}^{2}$ values of $50 \%$ to $75 \%$ indicated substantial heterogeneity, and $\mathrm{I}^{2}$ values of $75 \%$ to $100 \%$ indicated considerable heterogeneity $[34,35]$. The fixed-effect model (Mantel-Haenszel method) was utilized to calculate the pooled effects when $\mathrm{I}^{2}<50 \%$, and the random-effect model (DerSimonian-Laird method) was utilized to calculate the pooled effects when $\mathrm{I}^{2} \geq 50 \%$ [30]. Considering the low power of Cochran's $Q$ statistic, a $p$-value of 0.10 was used to determine statistical significance in the interpretation of heterogeneity [30]. Subgroup analyses were performed for the primary outcome and were employed to explore the source of heterogeneity among included studies. Vaccine effectiveness was calculated as 1-RR.

Sensitivity analyses were performed to quantitatively detect the robustness of the results. We estimated the robustness of the pooled effect of influenza vaccination for HWs by excluding studies one by one. Peters' and Harbord's tests were applied to determine the publication bias of dichotomous outcomes, including the incidence of laboratoryconfirmed influenza, ILI, and absenteeism. Egger's and Begg's tests were employed to identify publication bias in continuous outcomes. A $p$-value of 0.05 was considered to be an indicator of statistical significance, which implies that the publication bias among the included studies could not be ignored.

\section{Results}

After initial systematic searches, a total of 10,263 potentially relevant articles were identified. Of these, 2835 citations were removed due to duplication, 6913 reports were excluded based on a review of the title and abstract, 515 citations were fully screened, and 25 reports were included for final identification. Nine studies were excluded because of the lack of availability of the full text (incomplete data extraction, six; inapplicable study design, three). Consequently, a total of 16 studies (19 arms) were included in this systematic review and meta-analysis [36-51]. Details of the complete selection process of studies are shown in a PRISMA flow chart (Figure 1).

\subsection{Study Characteristics}

A total of 16 studies (19 arms) were included in this study, including six RCTs and ten cohort studies, which were published between 1988-2016. A total of 7971 participants were involved in the 16 studies, including 2745 from vaccinated groups and 5226 from control groups. The studies were carried out in nine countries, of which five were in Japan, two in the US, Italy, and China, separately, and five in other countries. The mean age of the HWs from the vaccinated and comparison groups ranged from $22-45$ years old and $22-44$ years old, respectively. Table 1 presents the detailed characteristics of the studies.

\subsection{Quality Assessment}

Of the six RCTs, four had moderate risks of bias and two had low risks of bias (Figure 2, Figure S1). Of the ten cohort studies, three displayed high quality and seven exhibited moderate quality (Table 2). 

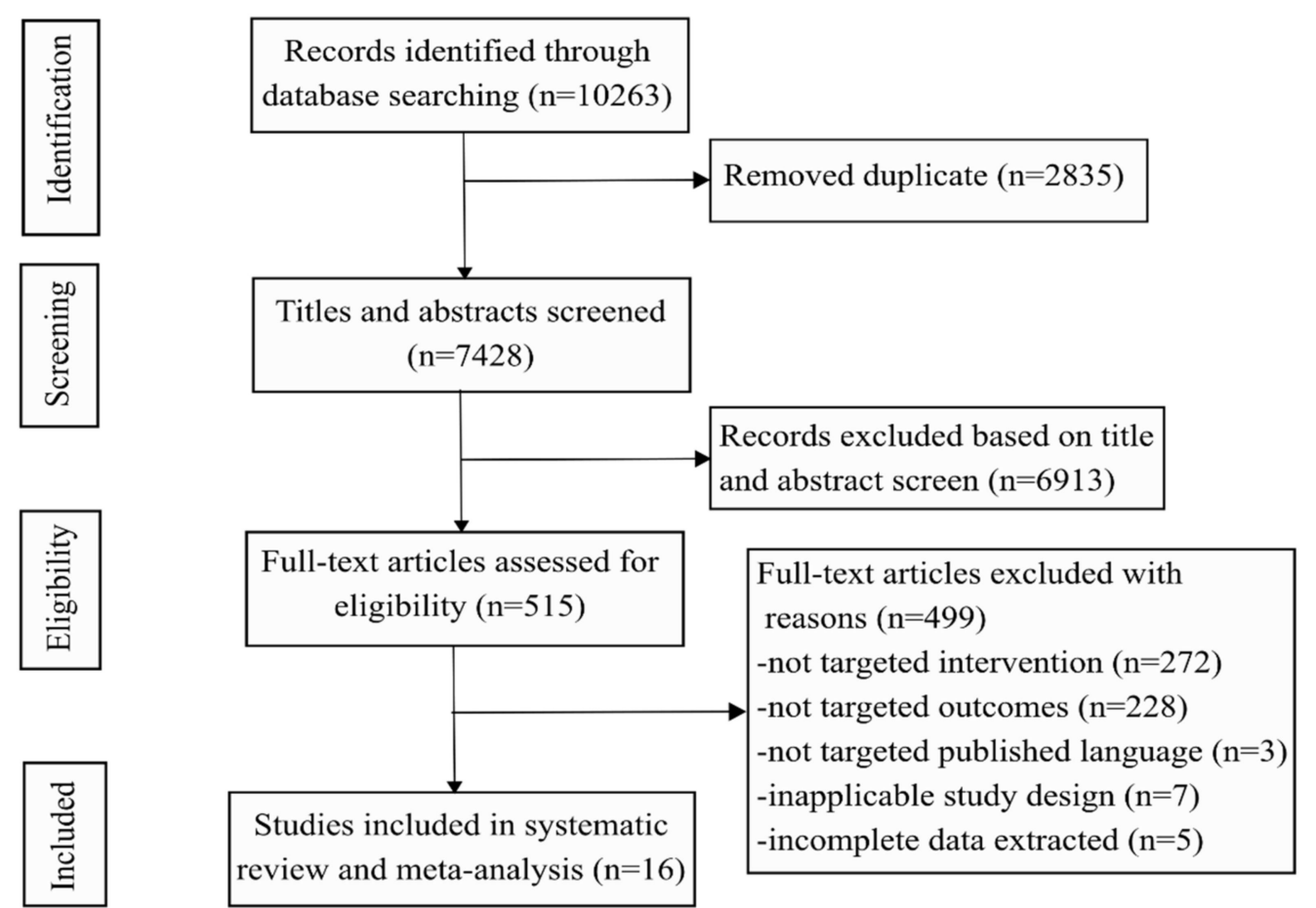

PubMed: 3162, Embase: 5713, CINAHL: 642, Cochrane Library: 504, Scopus: 40, CNKI: 53, Chinese Science and Technology Periodical Database:10, WanFang Database: 137, The Scientific Electronic Library Online (SciELO) database: 2

Figure 1. Flow diagram of study selection.

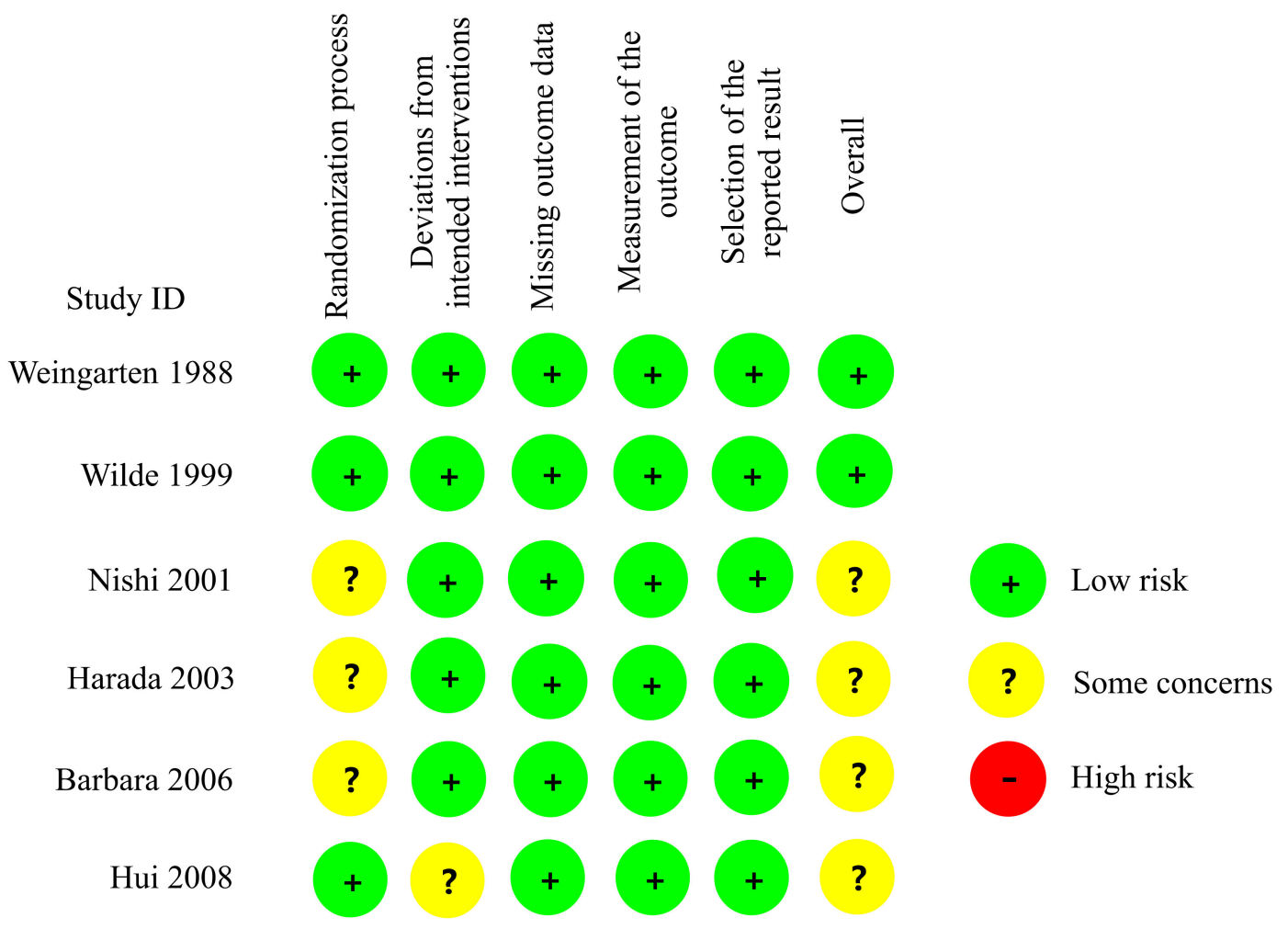

Figure 2. Quality assessment of the six randomized controlled trials. ID, identification. 
Table 1. Detailed information of included studies in the meta-analysis.

\begin{tabular}{|c|c|c|c|c|c|c|c|c|c|c|}
\hline $\begin{array}{c}\text { Author, Published } \\
\text { Year }\end{array}$ & $\begin{array}{c}\text { Conducted } \\
\text { Year }\end{array}$ & $\begin{array}{l}\text { Published } \\
\text { Language }\end{array}$ & Country & Source & $\begin{array}{c}\text { Study } \\
\text { Population }\end{array}$ & $\begin{array}{l}\text { Age Mean (SD) } \\
\text { exp./con. }\end{array}$ & $\begin{array}{l}\text { Sample Size } \\
\text { (exp./con.) }\end{array}$ & Comparison & Study Design & $\begin{array}{c}\text { Follow-Up } \\
\text { Period }\end{array}$ \\
\hline Weingarten, 1988 & $1985 / 1986$ & English & the US & Hospital & $\mathrm{HWs}^{\mathrm{a}}$ & $35.8(8.9) / 37.0(9.0)$ & $179(91 / 88)$ & Placebo (saline) & RCT & $14 \mathrm{~m}$ \\
\hline Jones, 1999 [37] & 1998 & English & Australia & Hospital & $\mathrm{HWs}^{\mathrm{b}}$ & - & $93(46 / 47)$ & \multirow{3}{*}{$\begin{array}{c}\text { Unvaccinated } \\
\text { Meningococcal } \\
\text { vaccine } \\
\text { Pneumococcal } \\
\text { vaccine } \\
\text { Placebo (saline) }\end{array}$} & cohort study & $5 \mathrm{~m}$ \\
\hline Wilde, 1999 [38] & 1993/1994 & English & the US & Hospital & $\mathrm{HWs}^{\mathrm{b}}$ & $28.0(2.8) / 28.3(3.3)$ & $103(51 / 52)$ & & $\mathrm{RCT}$ & $6 \mathrm{~m}$ \\
\hline Wilde, 1999 [38] & $1994 / 1995$ & English & the US & Hospital & $\mathrm{HWs}^{\mathrm{b}}$ & \multirow{2}{*}{$\begin{array}{c}30.0(5.1) / 30.8(5.9) \\
38.2(10.8) / 41.2(6.2) \\
40.8(12.0) \\
39.5(9.2) / 37.1(10.2)\end{array}$} & $156(78 / 78)$ & & $\mathrm{RCT}$ & $6 \mathrm{~m}$ \\
\hline Susa, 2001 [51] & $1999 / 2000$ & Japanese & Japan & Hospital & $\mathrm{HWs}^{\mathrm{a}}$ & & $362(196 / 166)$ & Unvaccinated & cohort study & $4 \mathrm{~m}$ \\
\hline Harada, 2003 [49] & $2000 / 2001$ & Japanese & Japan & Hospital & $\mathrm{HWs}^{\mathrm{a}}$ & $36.3 / 38.1$ & $348(159 / 189)$ & $\begin{array}{l}\text { Unvaccinated } \\
\text { Unvaccinated } \\
\text { city office staff }\end{array}$ & $\mathrm{RCT}$ & $4 \mathrm{~m}$ \\
\hline $\begin{array}{l}\text { Barbara, } 2006[39] \\
\text { Barbara, } 2006[39]\end{array}$ & $\begin{array}{l}2002 / 2003 \\
2003 / 2004\end{array}$ & $\begin{array}{l}\text { English } \\
\text { English }\end{array}$ & $\begin{array}{l}\text { Belgium } \\
\text { Belgium }\end{array}$ & $\begin{array}{l}\text { Hospital } \\
\text { Hospital }\end{array}$ & $\begin{array}{l}\mathrm{HWs}^{\mathrm{c}} \\
\mathrm{HWs}^{\mathrm{c}}\end{array}$ & $\begin{array}{c}42.4(1.1) / 40.0(1.5) \\
43.1(0.9) / 41.3(10.8)\end{array}$ & $\begin{array}{l}92(59 / 33) \\
72(36 / 36)\end{array}$ & $\begin{array}{l}\text { Unvaccinated } \\
\text { Unvaccinated }\end{array}$ & $\begin{array}{l}\text { RCT } \\
\text { RCT }\end{array}$ & $\begin{array}{l}6 \mathrm{~m} \\
5 \mathrm{~m}\end{array}$ \\
\hline Colombo, 2006 [40] & $2002 / 2003$ & English & Italy & Healthcare unit & HWs d & $44.3 / 43.2$ & $214(107 / 107)$ & Unvaccinated & cohort study & $4.5 \mathrm{~m}$ \\
\hline Ito, 2006 [41] & $2002 / 2003$ & English & Japan & Hospital & $\mathrm{HWs}^{\mathrm{a}}$ & $35.5(10.3) / 35.7(9.4)$ & $366(237 / 129)$ & Unvaccinated & cohort study & $4 \mathrm{~m}$ \\
\hline Liu, 2006 [50] & $2004 / 2005$ & Chinese & China & Hospital & $\mathrm{HWs}^{\mathrm{a}}$ & $40.5(10.3) / 38.4(10.9)$ & $952(487 / 465)$ & Unvaccinated & cohort study & $6 \mathrm{~m}$ \\
\hline Chan, 2007 [42] & $2004 / 2005$ & English & China & $\begin{array}{l}\text { Emergency } \\
\text { department }\end{array}$ & $\mathrm{HWs}^{\mathrm{e}}$ & $43.55(8.85) / 40.65(6.99)$ & $73(33 / 40)$ & Unvaccinated & cohort study & $10 \mathrm{~m}$ \\
\hline Hui, 2008 [43] & 2005 & English & Malaysia & $\begin{array}{l}\text { Faculty of } \\
\text { Dentistry }\end{array}$ & $\mathrm{HWs}^{\mathrm{a}}$ & $22.0(3.52) / 22.5(4.90)$ & $346(170 / 176)$ & Unvaccinated & RCT & $4 \mathrm{~m}$ \\
\hline Kheok, 2008 [46] & $2004 / 2005$ & English & Singapore & Hospital & $\mathrm{HWs}^{\mathrm{b}}$ & $37(11.3) / 33(9.1)$ & $541(211 / 330)$ & Unvaccinated & cohort study & $12 \mathrm{~m}$ \\
\hline Atamna, 2016 [44] & 2014 & English & Israel & Hospital & $\mathrm{HWs}^{\mathrm{b}}$ & $\begin{array}{c}43.15(12.06) / 39.32 \\
(10.85)\end{array}$ & $199(97 / 102)$ & Unvaccinated & cohort study & $4 \mathrm{~m}$ \\
\hline Ishikane, 2016 [47] & $2014 / 2015$ & English & Japan & $\begin{array}{l}\text { Long-term care } \\
\text { facility }\end{array}$ & $\mathrm{HWs}^{\mathrm{e}}$ & - & $338(288 / 50)$ & Unvaccinated & cohort study & $1 \mathrm{~m}$ \\
\hline
\end{tabular}

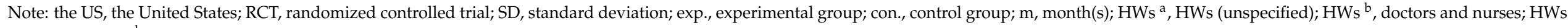

${ }^{c}$, doctors; $\mathrm{HWs}^{\mathrm{d}}$, doctors, nurses, and administrators; $\mathrm{HWs}^{\mathrm{e}}$, nurses. 
Table 2. Quality assessment of ten cohort studies.

\begin{tabular}{|c|c|c|c|c|c|c|c|c|c|}
\hline \multirow{2}{*}{$\begin{array}{c}\text { Author, } \\
\text { Published Year }\end{array}$} & \multicolumn{4}{|c|}{ Selection } & \multicolumn{2}{|c|}{ Comparability } & \multicolumn{2}{|c|}{ Outcome } & \multirow{2}{*}{ Total } \\
\hline & Item 1 & Item 2 & Item 3 & Item 4 & Item 5 & Item 6 & Item 7 & Item 8 & \\
\hline Jones, 1999 & 䊏 & 米 & 溇 & 米 & $\times$ & 米 & $\times$ & 溇 & 6 stars \\
\hline Colombo, 2006 & 啮 & 燐 & 数 & 啮 & 数 & 潾 & $x$ & 释 & 8 stars \\
\hline Ito, 2006 & 燐 & 潾 & 燐 & 潾 & $\times$ & $x$ & $x$ & 燐 & 5 stars \\
\hline Liu, 2006 & 潾 & 燐 & 燐 & 橉 & 潾 & $x$ & 潾 & 橉 & 8 stars \\
\hline Susa, 2006 & 潾 & 潾 & 数 & 潾 & $\times$ & $x$ & $x$ & 数 & 5 stars \\
\hline Chan, 2007 & 洗 & 洗 & 洗 & 棌 & $x$ & 谈 & $x$ & 谈 & 6 stars \\
\hline Kheok, 2008 & 燐 & 牲 & 燐 & 啮 & $x$ & 燐 & 数 & 燐 & 7 stars \\
\hline Amodio, 2010 & 数 & 数 & 燐 & 燐 & $\times$ & 燐 & $x$ & 燐 & 6 stars \\
\hline Atamna, 2016 & 䊁 & 次 & 燐 & 燐 & $x$ & 数 & $x$ & 数 & 6 stars \\
\hline Ishikane, 2016 & 䊁 & 䊁 & 燐 & 数 & $\times$ & 数 & $\times$ & 㭗 & 6 stars \\
\hline
\end{tabular}

Note: Item 1, Representativeness of the exposed cohort; Item 2, Selection of the non-exposed cohort; Item 3, Ascertainment of exposure; Item 4, Demonstration that outcome of interest was not present at start of study; Item 5, Comparability of cohorts on the basis of the design or analysis; Item 6, Assessment of outcome; Item 7, Whether follow-up was long enough for outcomes to occur; Item 8, Adequacy of follow-up of cohorts. the included study met the criteria of this item; $\times$, the included study did not meet the criteria of this item.

\subsection{Meta-Analysis}

3.3.1. Incidence of Laboratory-Confirmed Influenza

Differences in the incidence of laboratory-confirmed influenza were reported in two RCTs (including five arms) [38,39] and three cohort studies [41,44,47]. A total of 1428 HWs were enrolled, including 898 vaccinated HWs and 530 comparisons. Pooled effects using the fixed-effect model showed that vaccinated HWs were less likely to get an influenza infection than comparisons (pooled RR: $0.36,95 \%$ CI: 0.25 to $0.54, \mathrm{I}^{2}=9.7 \% ; p<0.001$, Figure 3), and that vaccine effectiveness (VE) was $64 \%$.

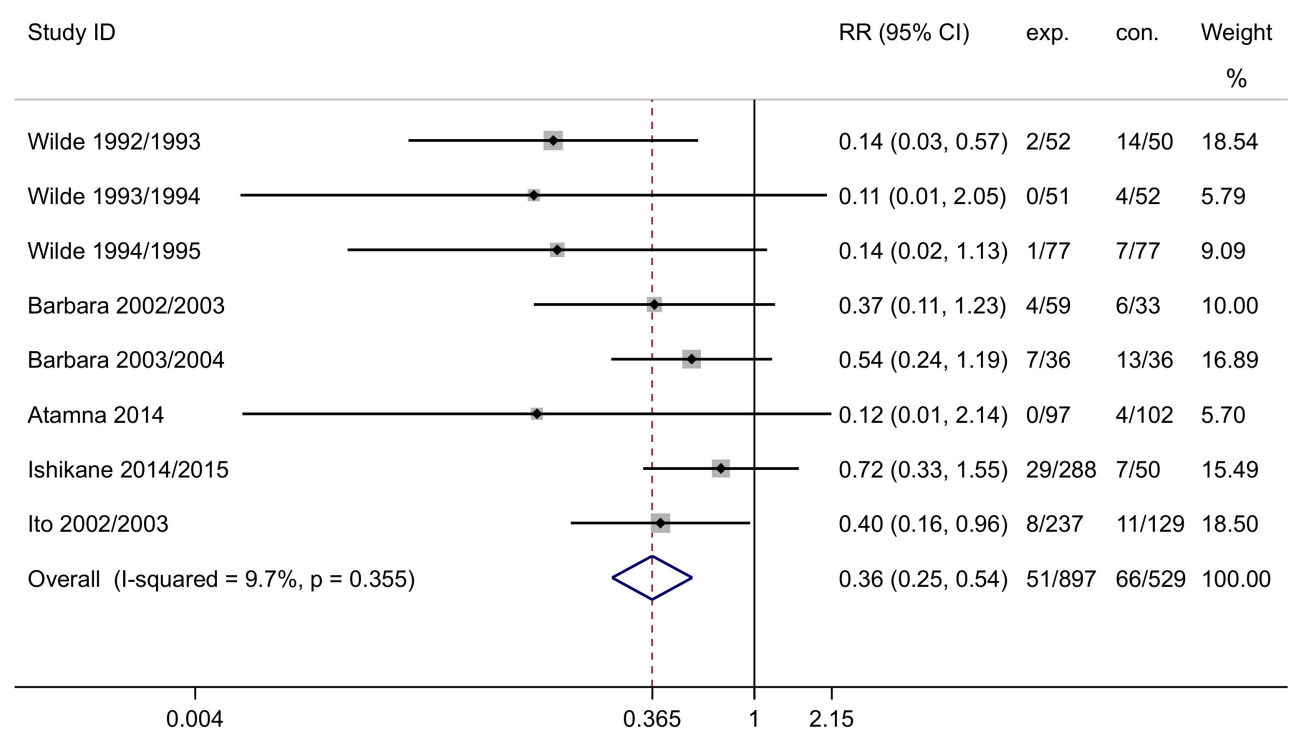

Figure 3. Forest plot of incidence of laboratory-confirmed influenza. ID, identification; exp., experimental group; con., control group; RR, risk ratio.

Subgroup analyses were conducted by country, study population, study design, and published year. The results indicated that influenza vaccination could significantly reduce the incidence of laboratory-confirmed influenza in different countries (Figure S2a), including the US (RR: $0.13,95 \%$ CI: 0.05 to 0.40 ), Belgium (RR: $0.48,95 \%$ CI: 0.25 to 0.92 ), and Japan (RR: $0.54,95 \%$ CI: 0.31 to 0.97 ). The VE values for the three subgroups were $87 \%$, $52 \%$, and $48 \%$, respectively. Regarding the study population, vaccination could decrease 
influenza infection among doctors and nurses (RR: 0.13 , 95\% CI: 0.05 to 0.37 , with $87 \%$ VE) and doctors alone (RR: 0.48, 95\% CI: 0.25 to 0.92, with 52\% VE; Figure S2b). Moreover, vaccination was effective in reducing the influenza incidence among HWs in studies with different study designs and published years (Figure S2c,d). Additionally, we divided the studies based on the average age of the experimental groups, and the results showed that the influenza vaccination works well for HWs in three age groups. The RRs for HWs aged under 30 years old, 30 to 40 years old, and more than 40 years old were 0.13 ( $95 \%$ CI: 0.04 to 0.48 ), 0.31 (95\% CI: 0.14 to 0.70 ), and 0.41 (95\% CI: 0.22 to 0.79 ), respectively (Figure S2e).

\subsubsection{Incidence of IL}

Eight studies reported the ILI incidence, including four RCTs [36,43,48,49] and four cohort studies $[44,46,50,51]$, which involved 1543 HWs from vaccination groups and $2211 \mathrm{HWs}$ from comparison groups. The results indicated an overall insignificant reduction of ILI incidence among vaccination groups compared with comparisons (combined RR: $0.69,95 \%$ CI: 0.45 to $1.06, p=0.087$, Figure 4 ). The forest plot showed substantial heterogeneity among these studies $\left(\mathrm{I}^{2}=87.2 \%\right)$. Therefore, we performed subgroup analyses to examine the source of heterogeneity. No statistical significance was found in different research regions: Asia (RR: $0.64,95 \%$ CI: 0.40 to $1.04, \mathrm{I}^{2}=89.1 \% ; p=0.074$ ); study populations: HWs (unspecified; RR: $0.64,95 \%$ CI: 0.37 to $1.08, \mathrm{I}^{2}=84.8 \% ; p=0.093$ ), doctors and nurses (RR: $0.69,95 \%$ CI: 0.45 to $1.06, \mathrm{I}^{2}=87.2 \% ; p=0.789$ ); average ages of vaccinated groups: $30-40$ years (RR: $0.63,95 \%$ CI: 0.35 to $1.16, \mathrm{I}^{2}=89.3 \% ; p=0.141$ ), $>40$ years (RR: $1.02,95 \%$ CI: 0.38 to $\left.2.75, \mathrm{I}^{2}=77.2 \% ; p=0.967\right)$. As for study design, the results demonstrated that a decreased incidence of ILI was reported in RCT studies (RR: $0.52,95 \%$ CI: 0.36 to 0.76 , $\mathrm{I}^{2}=56.8 \% ; p=0.001$, Figure S3a). The results also showed that influenza vaccination could effectively reduce the incidence of ILI within half a year of vaccination (RR: $0.45,95 \%$ CI: 0.35 to $0.57, \mathrm{I}^{2}=0.0 \% ; p<0.001$, Figure $\mathrm{S} 3 \mathrm{~b}$ ).

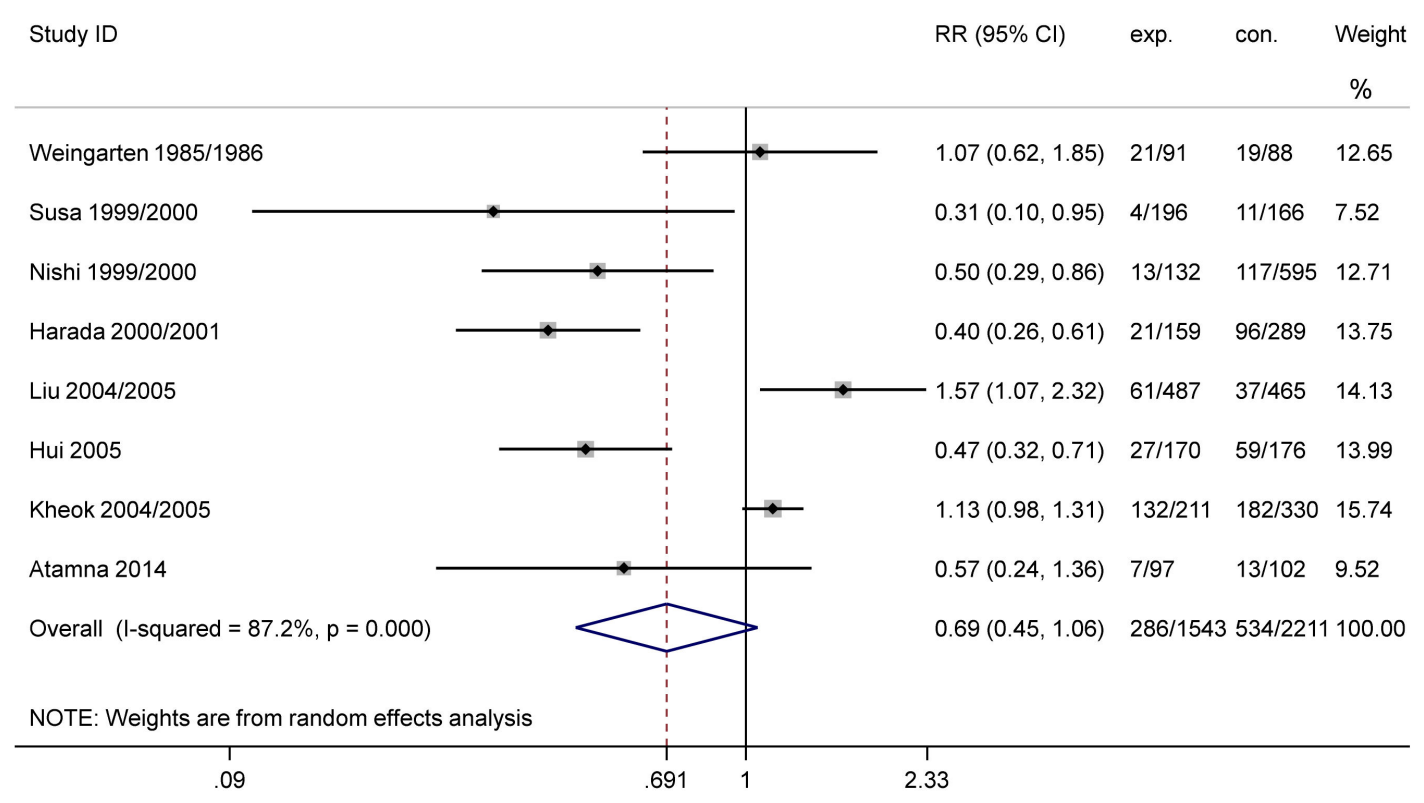

Figure 4. Forest plot of ILI incidence. ILI, influenza-like illness; ID, identification; exp., experimental group; con., control group; RR, risk ratio.

\subsubsection{Absenteeism Rate}

Six studies reported discrepancies in the absenteeism rate between vaccinated HWs and comparisons, which included $3475 \mathrm{HWs}$ (824/2651) from the US [36], Australia [37], Italy [40,45], China [42], and Malaysia [43]. Synthesis of the results revealed that the absenteeism rate decreased significantly among HWs exposed to influenza vaccination (overall 
RR: $0.63,95 \%$ CI: 0.46 to $0.86 ; p=0.004)$. However, there was moderate heterogeneity among these studies $\left(\mathrm{I}^{2}=54.3 \%\right)$.

\subsubsection{Workdays Lost}

The workdays lost among vaccination and comparison groups were reported in five studies [36,38,42,43,46], in which 1500 (686/814) HWs were enrolled. The pooled effect presented a significant decrease in workdays lost for vaccinated HWs in contrast to comparison groups (summarized SMD: $-0.18,95 \% \mathrm{CI}$ : -0.28 to $-0.07, \mathrm{I}^{2}=28.0 \%$; $p=0.001)$.

\subsection{Sensitivity Analyses and Publication Bias}

Sensitivity analyses were performed to determine the robustness of our results. Similar results were observed, indicating the robustness of our results (Figures S4-S7).

The results of Peters' and Harbord's tests for the binary outcomes of the incidence of laboratory-confirmed influenza (Peters': $p=0.397$; Harbord's: $p=0.082$ ), incidence of ILI (Peters': $p=0$. 646; Harbord's: $p=0.339$ ), and absenteeism rate (Peters': $p=0.924$; Harbord's: $p=0.167)$ concluded that publication bias could be ignored among the included studies. The $P$-values of Egger's test $(p=0.682)$ and Begg's test $(p=0.462)$ for the continuous outcome of workdays lost per person also indicated that there was no statistically significant difference in publication bias among the included studies.

\section{Discussion}

To the best of our knowledge, this study is the first to provide a comprehensive estimate of the effect of seasonal influenza vaccination on HWs with multiple outcomes, including the incidence of laboratory-confirmed influenza and ILI, absenteeism rate, and mean workdays lost. This study showed the benefits of influenza vaccination for HWs and indicated that vaccination could substantially reduce the incidence of laboratory-confirmed influenza infection by $64 \%$. Furthermore, the results demonstrated that vaccination is also beneficial for medical institutions, and that it may effectively reduce the absenteeism rate among HWs by $37 \%$ and lessen the workdays lost by 0.18 days/person among vaccinated HWs in contrast to comparison groups.

In this meta-analysis, we found that the effective reduction of laboratory-confirmed influenza infection among HWs could be observed in different subgroups, including different research districts, study populations, study designs, and published years, with a range of $52-87 \%$ VE. Subgroup analyses indicated that vaccination should be implemented in different subgroups, including doctors, nurses, and other HWs. Previous studies indicated that there is some risk of unvaccinated HWs transmitting the virus to patients [52]. As such, vaccination could provide indirect protection to family members and surrounding people [43], which emphasizes the necessity of vaccination for HWs. According to the recommendations of the $\mathrm{WHO}$, it is better to inoculate annually before a local influenza epidemic, and to match the local influenza virus strain [53]

In terms of the countries where studies were conducted, Japan reported the most related studies. Five out of sixteen studies were conducted in Japan, which included two RCTs and three cohort studies. Yet, the studies reported different outcomes: two studies reported the laboratory-confirmed incidence of influenza and three reported the incidence of ILI. The quality of all five studies was moderate, which may affect the accuracy of the results. Therefore, we performed a sensitivity analysis by removing studies conducted in Japan, but the pooled results of incidence of laboratory-confirmed influenza did not change remarkably (pooled RR: $0.27,95 \%$ CI: 0.16 to $0.47 ; \mathrm{I}^{2}=0.5 \%, p<0.001$ ), and the combined results of ILI incidence also showed only an insignificant change (integrated RR: 0.92, 95\% CI: 0.61 to $\left.1.39 ; \mathrm{I}^{2}=82.2 \%, p=0.685\right)$.

Our study suggests that ILI is not a recommended single indicator for evaluating the effectiveness of an influenza vaccination, and that a combination of laboratory data is needed. First, the definition of ILI is not unified. The CDC defines ILI as "a 
temperature of $\geq 100.0^{\circ} \mathrm{F}\left(\geq 37.8^{\circ} \mathrm{C}\right)$, oral or equivalent, and cough or sore throat, in the absence of a known cause other than influenza" [36,54], but there are other definitions in our included studies, which define ILI as "a febrile illness involving fever for a minimum of 1 day plus two or more of the following symptoms: cough, sore throat, runny nose, myalgia, malaise or headache" [43], or "acute onset of high fever (axillary temperature $\geq 38^{\circ} \mathrm{C}$ ), accompanied by 2 of the following symptoms, such as chills, weakness, headache, myalgia or joint pain, cough, sore throat and nasal congestion, nasopharynx redness and swelling" [50]. Besides, other respiratory viruses could also present as ILI, which makes the clinical differentiation of influenza from other pathogens difficult [55]. In addition, the assessment of ILI depends on the clinical reporting of patients, which may cause bias if inaccurate data are provided [56]. Finally, a previous study concluded that ILI has no role in measuring influenza VE [57]. This may explain the substantial heterogeneities in the pooled results of the incidence of ILI.

Our findings provide convincing evidence of the effect of the influenza vaccination for HWs. Vaccination is imperative, especially for countries and areas in which influenza vaccination coverage rates are low for HWs, like China [14,15] and Italy [13]. Besides the reports included in this study, other excluded citations with incomplete data also reported that influenza vaccination was considerably useful in limiting the length of absenteeism [58-60] and workdays lost [58-61]. Furthermore, vaccination is cost-efficient for medical institutions since it may save overall costs for hospitals or other medical departments, given that expenditure on absent HWs caused by influenza totals more than the cost of vaccination activities $[40,50,59,60,62,63]$, which is in accordance with a previous meta-analysis [33].

Some actions might be conducive to improving influenza vaccine coverage among HWs. First, national policies and normative guidelines regarding influenza vaccination for HWs should be published as soon as possible, as studies indicate that mandatory influenza vaccination policies are more effective than nonmandatory policies in reducing the rate of absenteeism among HWs [64,65]. Second, financial subsidies for influenza vaccination may ensure that HWs can be inoculated for free. Alternatively, it is advisable that the medical insurance of HWs should fully, or mostly, cover the costs of influenza vaccinations. One study indicated that some local reimbursement policies regarding influenza vaccination only covered a small part of the population in China [66]. Third, the investment in scientific research and development for the influenza vaccine should be increased, to improve the efficacy of the vaccine, since some reports indicated that the VE was low in many countries, like Japan [47] and Canada [67]. Fourth, the awareness of HWs regarding influenza vaccinations should be improved, as awareness promotes a positive attitude that results in improved practices. Further effort is necessary to increase the HWs' awareness regarding influenza vaccination. Suitable awareness initiatives include, for instance, sending textmessage/e-amils when influenza season comes, implementing peer support (i.e., support from others HWs with high awareness of influenza vaccinations), conducting targeted training courses to pursue the academic detailing methodology [68,69], providing in-service education [70,71], and implementing awareness campaigns [68,72]. Last, vaccination healthcare services should be improved, such as vaccine supply, accessibility of services, and notifications of potential side effects.

There are several limitations to our study. First, only sixteen studies from nine countries were included in the meta-analysis, and papers published in other languages were not taken into consideration, so the results cannot be generalized without further validation. Moreover, sixteen studies were conducted before the outbreak of COVID-19. Some reports have indicated that COVID-19 and influenza have coinfections [73-75], which might affect seasonal influenza vaccination effects. Second, only three high-quality studies were included. More high-quality studies are required to explore influenza vaccination effectiveness among HWs. Third, for the secondary outcomes of the absenteeism rate and workdays lost, the included studies and sample sizes were relatively small, and there was heterogeneity of the work structure between healthcare settings, which might affect the 
interpretation of our results regarding the two outcomes. Overall, more studies are needed to provide scientific evidence in more countries.

\section{Conclusions}

This systematic review and meta-analysis provides evidence that influenza vaccination plays a crucial role in reducing the incidence of laboratory-confirmed influenza, absenteeism rates, and mean workdays lost among HWs. It is advisable to improve the coverage and increase influenza vaccination counts for HWs, which may benefit HWs and medical institutions alike.

Supplementary Materials: The following are available online at https:/ / www.mdpi.com/article/ 10.3390/vaccines9101104/s1, Figure S1. Overall quality assessment of randomized controlled trials included in this study. Figure S2. Subgroup analysis of incidence of lab-confirmed influenza. Figure S3. Subgroup analysis of ILI. Figure S4. Sensitivity analysis regarding the outcome of the incidence of lab-confirmed influenza. Figure S5. Sensitivity analysis regarding the outcome of the incidence of ILI. Figure S6. Sensitivity analysis regarding the outcome of absenteeism rate. Figure S7. Sensitivity analysis regarding the outcome of workdays lost per person.

Author Contributions: L.Q. conceived and designed the study, wrote and registered the protocol, performed a holistic literature search from all databases, reviewed full texts for inclusion, supervised the research, and obtained funding. L.F. conceived and designed the study, supervised the research, conducted the literature search, and provided thoughtful reviews for manuscript revision. T.L. and X.Q. contributed to the data acquisition, including literature screening, quality assessment, and data extraction. T.L. performed the formal data analysis and drafted the manuscript. Q.L. supervised the research and provided thoughtful reviews for manuscript revision. M.J. provided thoughtful reviews for manuscript revision and data interpretation. W.Y., W.T., K.S., Y.X. (Yu Xia) and Y.X. (Yu Xiong) participated in the acquisition and interpretation of data and the revision of the manuscript. All authors were involved in data interpretation and made substantial contributions to critically revising the manuscript before submission. All authors have read and agreed to the published version of the manuscript.

Funding: This work was funded by Chinese Academy of Medical Sciences (CAMS) Innovation Fund for Medical Sciences (No. 2020-I2M-1-001), and Senior Medical Talents Program of Chongqing for Young and Middle-aged from Chongqing Health Commission Program (No. 2019GDRC014).

Institutional Review Board Statement: Not applicable.

Informed Consent Statement: Not applicable.

Data Availability Statement: Data sharing is not applicable in this systematic review and metaanalysis. Data used in this study are available from the included published papers.

Acknowledgments: We would like to thank Lisa Grohskopf, Ashley Fowlkers, Eduardo AzzizBaumgartner and Alexander Millman of the US Centers for Disease Control and Prevention for their valuable advice and effort on the protocol of this study. Special thanks go to Jinyu He from Chongqing Municipal Center for Disease Control and Prevention and Yingsong Jiang from Chongqing People's Hospital for their translation of the Japanese articles included.

Conflicts of Interest: The authors declare no conflict of interest.

\section{References}

1. Iuliano, A.D.; Roguski, K.M.; Chang, H.H.; Muscatello, D.J;; Palekar, R.; Tempia, S.; Cohen, C.; Gran, J.M.; Schanzer, D.; Cowling, B.J.; et al. Estimates of global seasonal influenza-associated respiratory mortality: A modelling study. Lancet 2018, 391, 1285-1300. [CrossRef]

2. Paget, J.; Spreeuwenberg, P.; Charu, V.; Taylor, R.J.; Iuliano, A.D.; Bresee, J.; Simonsen, L.; Viboud, C. Global mortality associated with seasonal influenza epidemics: New burden estimates and predictors from the GLaMOR Project. J. Glob. Health 2019, 9, 020421. [CrossRef]

3. Lietz, J.; Westermann, C.; Nienhaus, A.; Schablon, A. The Occupational Risk of Influenza A (H1N1) Infection among Healthcare Personnel during the 2009 Pandemic: A Systematic Review and Meta-Analysis of Observational Studies. PLoS ONE 2016, 11, e0162061. [CrossRef] [PubMed]

4. Srinivasan, A.; Perl, T.M. Respiratory protection against influenza. JAMA 2009, 302, 1903-1904. [CrossRef] [PubMed] 
5. Kuster, S.P.; Shah, P.S.; Coleman, B.L.; Lam, P.P.; Tong, A.; Wormsbecker, A.; McGeer, A. Incidence of influenza in healthy adults and healthcare workers: A systematic review and meta-analysis. PLoS ONE 2011, 6, e26239. [CrossRef] [PubMed]

6. Durando, P.; Alicino, C.A.-O.; Dini, G.; Barberis, I.; Bagnasco, A.M.; Iudici, R.; Zanini, M.; Martini, M.; Toletone, A.; Paganino, C.; et al. Determinants of adherence to seasonal influenza vaccination among healthcare workers from an Italian region: Results from a cross-sectional study. BMJ Open 2016, 6, e010779. [CrossRef]

7. World Health Organization. Global Influenza Strategy 2019-2030. Available online: https://apps.who.int/iris/handle/10665/31 1184 (accessed on 5 March 2020).

8. World Health Organization. Vaccines against influenza WHO position paper-November 2012. Wkly. Epidemiol. Rec. 2012, 87, 461-476.

9. Maltezou, H.C.; Botelho-Nevers, E.; Brantsaeter, A.B.; Carlsson, R.M.; Heininger, U.; Hubschen, J.M.; Josefsdottir, K.S.; Kassianos, G.; Kyncl, J.; Ledda, C.; et al. Vaccination of healthcare personnel in Europe: Update to current policies. Vaccine 2019, 37, 7576-7584. [CrossRef]

10. Dini, G.; Toletone, A.; Sticchi, L.; Orsi, A.; Bragazzi, N.L.; Durando, P. Influenza vaccination in healthcare workers: A comprehensive critical appraisal of the literature. Hum. Vaccin. Immunother. 2018, 14, 772-789. [CrossRef]

11. Black, C.L.; Yue, X.; Ball, S.W.; Fink, R.V.; de Perio, M.A.; Laney, A.S.; Williams, W.W.; Graitcer, S.B.; Fiebelkorn, A.P.; Lu, P.J.; et al. Influenza Vaccination Coverage Among Health Care Personnel-United States, 2017-2018 Influenza Season. Morb. Mortal. Wkly. Rep. 2018, 67, 1050-1054. [CrossRef]

12. Public Health England. Seasonal flu Vaccine Uptake in Healthcare Workers: Monthly Data, 2020 to 2021. Available online: https: / / www.gov.uk/government/statistics/seasonal-flu-vaccine-uptake-in-healthcare-workers-monthly-data-2020-to-2021. (accessed on 2 February 2021).

13. To, K.W.; Lai, A.; Lee, K.C.; Koh, D.; Lee, S.S. Increasing the coverage of influenza vaccination in healthcare workers: Review of challenges and solutions. J. Hosp. Infect. 2016, 94, 133-142. [CrossRef]

14. Yu, J.; Ren, X.; Ye, C.; Tian, K.; Feng, L.; Song, Y.; Cowling, B.J.; Li, Z. Influenza Vaccination Coverage among Registered Nurses in China during 2017-2018: An Internet Panel Survey. Vaccines 2019, 7, 134. [CrossRef]

15. Song, Y.; Zhang, T.; Chen, L.; Yi, B.; Hao, X.; Zhou, S.; Zhang, R.; Greene, C. Increasing seasonal influenza vaccination among high risk groups in China: Do community healthcare workers have a role to play? Vaccine 2017, 35, 4060-4063. [CrossRef] [PubMed]

16. Vasilevska, M.; Ku, J.; Fisman, D.N. Factors associated with healthcare worker acceptance of vaccination: A systematic review and meta-analysis. Infect. Control Hosp. Epidemiol. 2014, 35, 699-708. [CrossRef]

17. Haridi, H.K.; Salman, K.A.; Basaif, E.A.; Al-Skaibi, D.K. Influenza vaccine uptake, determinants, motivators, and barriers of the vaccine receipt among healthcare workers in a tertiary care hospital in Saudi Arabia. J. Hosp. Infect. 2017, 96, 268-275. [CrossRef] [PubMed]

18. Cherian, T.; Morales, K.F.; Mantel, C.; Lambach, P.; Independent Expert Advisory Group for Health Worker Influenza Vaccination. Factors and considerations for establishing and improving seasonal influenza vaccination of health workers: Report from a WHO meeting, January 16-17, Berlin, Germany. Vaccine 2019, 37, 6255-6261. [CrossRef]

19. Pereira, M.; Williams, S.; Restrick, L.; Cullinan, P.; Hopkinson, N.S. Healthcare worker inflfluenza vaccination and sickness absence-An ecological study. Clin. Med. 2017, 17, 484-489. [CrossRef]

20. Ng, A.N.M.; Lai, C.K.Y. Effectiveness of seasonal influenza vaccination in healthcare workers: A systematic review. J. Hosp. Infect. 2011, 79, 279-286. [CrossRef] [PubMed]

21. Lorenc, T.; Marshall, D.; Wright, K.; Sutcliffe, K.; Sowden, A. Seasonal influenza vaccination of healthcare workers: Systematic review of qualitative evidence. BMC Health Serv. Res. 2017, 17, 732. [CrossRef]

22. Lemaitre, M.; Meret, T.; Rothan-Tondeur, M.; Belmin, J.; Lejonc, J.L.; Luquel, L.; Piette, F.; Salom, M.; Verny, M.; Vetel, J.M.; et al Effect of influenza vaccination of nursing home staff on mortality of residents: A cluster-randomized trial. J. Am. Geriatr. Soc. 2009, 57, 1580-1586. [CrossRef]

23. Burls, A.; Jordan, R.; Barton, P.; Olowokure, B.; Wake, B.; Albon, E.; Hawker, J. Vaccinating healthcare workers against influenza to protect the vulnerable-is it a good use of healthcare resources? A systematic review of the evidence and an economic evaluation. Vaccine 2006, 24, 4212-4221. [CrossRef]

24. Liberati, A.; Altman, D.G.; Tetzlaff, J.; Mulrow, C.; Gøtzsche, P.C.; Ioannidis, J.P.A.; Clarke, M.; Devereaux, P.; Kleijnen, J.; Moher, D. The PRISMA statement for reporting systematic reviews and meta-analyses of studies that evaluate healthcare interventions: Explanation and elaboration. BMJ 2009, 339, b2700. [CrossRef]

25. Moher, D.; Liberati, A.; Tetzlaff, J.; Altman, D.G.; PRISMA Group. Preferred reporting items for systematic reviews and meta-analyses: The PRISMA statement. BMJ 2009, 339, b2535. [CrossRef]

26. Centers for Disease Control and Prevention. Available online: https://www.cdc.gov/vaccines/adults/rec-vac/hcw.html (accessed on 10 October 2019).

27. Li, Q.; Eduardo, A.-B.; Carolyn, M.G.; Luzhao, F.; Wenge, T.; Lisa, A.G.; Ashley, C.F.; Alexander, J.M. The Effect of Seasonal Influenza Vaccination on Healthcare Workers: Protocol for a Systematic Review and Meta-Analysis. PROSPERO 2020 CRD42020162226. Available online: https://www.crd.york.ac.uk/prospero/display_record.php?ID=CRD42020162226 (accessed on 28 April 2020).

28. Grey Literature Network Service 2021. GreyNet International. Available online: http://www.greynet.org/ (accessed on 1 September 2021). 
29. Cumpston, M.; Li, T.; Page, M.J.; Chandler, J.; Welch, V.A.; Higgins, J.P.; Thomas, J. Updated guidance for trusted systematic reviews: A new edition of the Cochrane Handbook for Systematic Reviews of Interventions. Cochrane Database Syst. Rev. 2019, 10, ED000142. [CrossRef]

30. Higgins, J.P.T.T.J.; Chandler, J.; Cumpston, M.; Li, T.; Page, M.J.; Welch, V.A. (Eds.) Cochrane Handbook for Systematic Reviews of Interventions; Cochrane: London, UK, 2021; Version 6.2 (Updated February 2021). Available online: www.training.cochrane.org/ handbook (accessed on 1 March 2021).

31. Sterne, J.A.C.; Savovic, J.; Page, M.J.; Elbers, R.G.; Blencowe, N.S.; Boutron, I.; Cates, C.J.; Cheng, H.Y.; Corbett, M.S.; Eldridge, S.M.; et al. RoB 2: A revised tool for assessing risk of bias in randomised trials. BMJ 2019, 366, 14898. [CrossRef]

32. Stang, A. Critical evaluation of the Newcastle-Ottawa scale for the assessment of the quality of nonrandomized studies in meta-analyses. Eur. J. Epidemiol. 2010, 25, 603-605. [CrossRef]

33. Imai, C.; Toizumi, M.; Hall, L.; Lambert, S.; Halton, K.; Merollini, K. A systematic review and meta-analysis of the direct epidemiological and economic effects of seasonal influenza vaccination on healthcare workers. PLoS ONE 2018, 13, e0198685. [CrossRef] [PubMed]

34. Higgins, J.P.; Thompson, S.G. Quantifying heterogeneity in a meta-analysis. Stat. Med. 2002, 21, 1539-1558. [CrossRef] [PubMed]

35. Thakkinstian, A.; McElduff, P.; D’Este, C.; Duffy, D.; Attia, J. A method for meta-analysis of molecular association studies. Stat Med. 2005, 24, 1291-1306. [CrossRef] [PubMed]

36. Weingarten, S.; Staniloff, H.; Ault, M.; Miles, P.; Bamberger, M.; Meyer, R.D. Do hospital employees benefit from the influenza vaccine? A placebo-controlled clinical trial. J. Gen. Intern. Med. 1988, 3, 32-37. [CrossRef] [PubMed]

37. Jones, C. Influenza vaccination: Impact on absenteeism among nursing and medical staff in a metropolitan teaching hospital. Aust. Infect. Control. 1999, 4, 14-17. [CrossRef]

38. Wilde, J.A.; McMillan, J.A.; Serwint, J.; Butta, J.; O’Riordan, M.A.; Steinhoff, M.C. Effectiveness of influenza vaccine in health care professionals: A randomized trial. JAMA 1999, 281, 908-913. [CrossRef]

39. Michiels, B.; Philips, H.; Coenen, S.; Yane, F.; Steinhauser, T.; Stuyck, S.; Denekens, J.; Van Royen, P. The effect of giving influenza vaccination to general practitioners: A controlled trial [NCT00221676]. BMC Med. 2006, 4, 17.

40. Colombo, G.L.; Ferro, A.; Vinci, M.; Zordan, M.; Serra, G. Cost-benefit analysis of influenza vaccination in a public healthcare unit. Ther. Clin. Risk Manag. 2006, 2, 219-226. [CrossRef] [PubMed]

41. Ito, Y.; Sumi, H.; Kato, T. Evaluation of influenza vaccination in health-care workers, using rapid antigen detection test. J. Infect. Chemother. 2006, 12, 70-72. [CrossRef]

42. Chan, S.S.-W. Does vaccinating ED health care workers against influenza reduce sickness absenteeism? Am. J. Emerg. Med. 2007, 25, 808-811. [CrossRef] [PubMed]

43. Hui, L.S.; Hesahm, R.B.; Jaafar, M.H.b.; Hussaini, H.M.; Isahak, D.I. Effectiveness of inflfluenza vaccine in preventing inflfluenzalike illness among Faculty of Dentistry staff and students in Universiti Kebangsaan Malaysia. Healthc. Infect. 2008, 13, 4-9.

44. Atamna, Z.; Chazan, B.; Nitzan, O.; Colodner, R.; Kfir, H.; Strauss, M.; Schwartz, N.; Markel, A. Seasonal Influenza Vaccination Effectiveness and Compliance among Hospital Health Care Workers. Isr. Med. Assoc. J. 2016, 18, 5-9.

45. Amodio, E.; Pasquale, M.D.; Anastasi, G.; Gelsomino, V.; Morici, M.; Romano, N.; Torregrossa, M.V.; Cannova, L.; Calamusa, G.; Firenze, A. Influenza vaccination among healthcare workers and absenteeism from work due to influenza-like illness in a teaching hospital in Palermo. Ital. J. Public Health 2010, 7, 311-318.

46. Kheok, S.W.; Chong, C.Y.; McCarthy, G.; Lim, W.Y.; Goh, K.T.; Razak, L.; Tee, N.W.S.; Tambyah, P.A. The efficacy of influenza vaccination in healthcare workers in a tropical setting: A prospective investigator blinded observational study. Ann. Acad. Med. Singap. 2008, 37, 465-469.

47. Ishikane, M.; Kamiya, H.; Kawabata, K.; Higashihara, M.; Sugihara, M.; Tabuchi, A.; Kuwabara, M.; Yahata, Y.; Yamagishi, T.; Odagiri, T.; et al. Seasonal influenza vaccine (A/New York/39/2012) effectiveness against influenza A virus of health care workers in a long term care facility attached with the hospital, Japan, 2014/15: A cohort study. J. Infect. Chemother. 2016, 22, 777-779. [CrossRef]

48. Nishi, K.; Mizuguchi, M.; Ueda, A. Effectiveness of influenza vaccine in health-care workers. Kansenshogaku Zasshi 2001, 75, 851-855. [CrossRef] [PubMed]

49. Harada, H.; Kobayashi, T.; Wakamoto, Y.; Takita, S.; Sugiyama, S.; Kunitsugu, I.; Okuda, M.; Houbara, T. The efficacy and problems with influenza vaccination among hospital workers. Nihon Koshu Eisei Zasshi 2003, 50, 547-552. [PubMed]

50. Min, L.; Gai-Fen, L.; Wei, Z.; Yan, W.; Li, W.; Shi, W. An Effect and Cost-Benefit Analysis of Influenza Vaccine among the Healthcare Worker. Chin. Gen. Pract. 2006, 9, 708-711.

51. Ritsuko, S.; Katsuya, F.; Masaki, I.; Masako, N.; Hiroki, T. Effectiveness of Influenza Vaccine in Hospital Workers. Environ. Infect. 2001, 16, 303-308.

52. Riphagen-Dalhuisen, J.; Burgerhof, J.G.; Frijstein, G.; Geest-Blankert, v.d.A.D.; Danhof-Pont, M.B.; de Jager, H.J.; Bos, A.A.; Smeets, E.E.; de Vries, M.J.; Gallee, P.M.; et al. Hospital-based cluster randomised controlled trial to assess effects of a multi-faceted programme on influenza vaccine coverage among hospital healthcare workers and nosocomial influenza in the Netherlands, 2009 to 2011. Euro. Surveill. 2013, 18, 20512. [CrossRef]

53. World Health Organization. Vaccination Timing. Available online: https://www.who.int/influenza/vaccines/tropics/ vaccination_timing/en/ (accessed on 3 August 2019). 
54. Centers for Disease Control and Prevention (CDC). Influenza Activity-United States, 2012-2013 season and composition of the 2013-14 influenza vaccine. MMWR Morb. Mortal. Wkly. Rep. 2013, 62, 473-479.

55. World Health Organization. Influenza (Seasonal). Available online: https://www.who.int/news-room/fact-sheets/detail/ influenza-(seasonal) (accessed on 18 May 2021).

56. Lee, V.J.; Chen, M.I.; Yap, J.; Ong, J.; Lim, W.Y.; Lin, R.T.; Barr, I.; Ong, J.B.; Mak, T.M.; Goh, L.G.; et al. Comparability of different methods for estimating influenza infection rates over a single epidemic wave. Am. J. Epidemiol. 2011, 174, 468-478. [CrossRef]

57. Thomas, R.E. Is influenza-like illness a useful concept and an appropriate test of influenza vaccine effectiveness? Vaccine 2014, 32, 2143-2149. [CrossRef]

58. Gianino, M.M.; Politano, G.; Scarmozzino, A.; Charrier, L.; Testa, M.; Giacomelli, S.; Benso, A.; Zotti, C.M. Estimation of sickness absenteeism among Italian healthcare workers during seasonal influenza epidemics. PLoS ONE 2017, 12, e0182510. [CrossRef]

59. Zaffina, S.; Gilardi, F.; Rizzo, C.; Sannino, S.; Brugaletta, R.; Santoro, A.; Castelli Gattinara, G.; Ciofi Degli Atti, M.L.; Raponi, M.; Vinci, M.R. Seasonal influenza vaccination and absenteeism in health-care workers in two subsequent influenza seasons (2016/17 and 2017/18) in an Italian pediatric hospital. Expert Rev. Vaccines 2019, 18, 411-418. [CrossRef]

60. Van Buynder, P.G.; Konrad, S.; Kersteins, F.; Preston, E.; Brown, P.D.; Keen, D.; Murray, N.J. Healthcare worker influenza immunization vaccinate or mask policy: Strategies for cost effective implementation and subsequent reductions in staff absenteeism due to illness. Vaccine 2015, 33, 1625-1628. [CrossRef]

61. Saxen, H.; Virtanen, M. Randomized, placebo-controlled double blind study on the efficacy of influenza immunization on absenteeism of health care workers. Pediatr. Infect. Dis. J. 1999, 18, 779-783. [CrossRef]

62. Yassi, A.; Kettner, J.; Hammond, G.; Cheang, M.; McGill, M. Effectiveness and cost-benefit of an influenza vaccination program for health care workers. Can. J. Infect. Dis. 1991, 2, 101-108. [CrossRef]

63. Chan, A.L.F.; Shie, H.-J.; Lee, Y.-J.; Lin, S.-J. The evaluation of free influenza vaccination in health care workers in a medical center in Taiwan. Pharm. World Sci. 2008, 30,39-43. [CrossRef]

64. Frederick, J.; Brown, A.C.; Cummings, D.A.; Gaydos, C.A.; Gibert, C.L.; Gorse, G.J.; Los, J.G.; Nyquist, A.C.; Perl, T.M.; Price, C.S.; et al. Protecting Healthcare Personnel in Outpatient Settings: The Influence of Mandatory Versus Nonmandatory Influenza Vaccination Policies on Workplace Absenteeism During Multiple Respiratory Virus Seasons. Infect. Control Hosp. Epidemiol. 2018, 39, 452-461. [CrossRef]

65. Murti, M.; Otterstatter, M.; Orth, A.; Balshaw, R.; Halani, K.; Brown, P.D.; Hejazi, S.; Thompson, D.; Allison, S.; Bharmal, A.; et al. Measuring the impact of influenza vaccination on healthcare worker absenteeism in the context of a province-wide mandatory vaccinate-or-mask policy. Vaccine 2019, 37, 4001-4007. [CrossRef] [PubMed]

66. Yang, J.; Atkins, K.E.; Feng, L.; Pang, M.; Zheng, Y.; Liu, X.; Cowling, B.J.; Yu, H. Seasonal influenza vaccination in China: Landscape of diverse regional reimbursement policy, and budget impact analysis. Vaccine 2016, 34, 5724-5735. [CrossRef] [PubMed]

67. Gilca, R.; Skowronski, D.M.; Douville-Fradet, M.; Amini, R.; Boulianne, N.; Rouleau, I.; Martineau, C.; Charest, H.; De Serres, G. Mid-Season Estimates of Influenza Vaccine Effectiveness against Influenza A(H3N2) Hospitalization in the Elderly in Quebec, Canada, January 2015. PLoS ONE 2015, 10, e0132195. [CrossRef] [PubMed]

68. Bert, F.; Thomas, R.; Lo Moro, G.; Scarmozzino, A.; Silvestre, C.; Zotti, C.M.; Siliquini, R. A new strategy to promote flu vaccination among health care workers: Molinette Hospital's experience. J. Eval. Clin. Pract. 2020, 26, 1205-1211. [CrossRef] [PubMed]

69. Tamburrano, A.; Mellucci, C.; Galletti, C.; Vitale, D.; Vallone, D.; Barbara, A.; Sguera, A.; Zega, M.; Damiani, G.; Laurenti, P. Improving Nursing Staff Attitudes toward Vaccinations through Academic Detailing: The HProImmune Questionnaire as a Tool for Medical Management. Int. J. Environ. Res. Public Health 2019, 16, 2006. [CrossRef]

70. Alshammari, T.M.; Yusuff, K.B.; Aziz, M.M.; Subaie, G.M. Healthcare professionals' knowledge, attitude and acceptance of influenza vaccination in Saudi Arabia: A multicenter cross-sectional study. BMC Health Serv. Res. 2019, 19, 229. [CrossRef] [PubMed]

71. Andayi, F.; Emukule, G.O.; Osoro, E.; Ndegwa, L.K.; Otiato, F.; Muturi, P.; Azziz-Baumgartner, E.; Kalani, R.; Anyango, E.; Muthoka, P.M.; et al. Knowledge and attitude of Kenyan healthcare workers towards pandemic influenza disease and vaccination: 9 years after the last influenza pandemic. Vaccine 2021, 39, 3991-3996. [CrossRef] [PubMed]

72. Choucair, K.; El Sawda, J.; Assaad, S.; El Chakhtoura, N.G.; Hassouna, H.; Sidani, N.; Yasmin, M.; Rteil, A.; Kanj, S.S.; Kanafani, Z.A. Knowledge, Perception, Attitudes and Behavior on Influenza Immunization and the Determinants of Vaccination. J. Epidemiol. Glob. Health 2021, 11, 34-41. [CrossRef]

73. Cuadrado-Payan, E.; Montagud-Marrahi, E.; Torres-Elorza, M.; Bodro, M.; Blasco, M.; Poch, E.; Soriano, A.; Pineiro, G.J. SARS-CoV-2 and influenza virus co-infection. Lancet 2020, 395, e84. [CrossRef]

74. Cheng, Y.; Ma, J.; Wang, H.; Wang, X.; Hu, Z.; Li, H.; Zhang, H.; Liu, X. Co-infection of influenza A virus and SARS-CoV-2: A retrospective cohort study. J. Med. Virol. 2021, 93, 2947-2954. [CrossRef]

75. Fahim, M.; Ghonim, H.A.E.S.; Roshdy, W.H.; Naguib, A.; Elguindy, N.; AbdelFatah, M.; Hassany, M.; Mohsen, A.; Afifi, S.; Eid, A. Coinfection With SARS-CoV-2 and Influenza A(H1N1) in a Patient Seen at an Influenza-like Illness Surveillance Site in Egypt: Case Report. JMIR Public Health Surveill. 2021, 7, e27433. [CrossRef] 